\title{
Análise do acabamento superficial e força de corte no torneamento de alumina a verde
}

\author{
Analysis of surface finish and cutting force in \\ turning of green alumina
}

\author{
Marcos Gonçalves Júnior ${ }^{1}$, Luiz Eduardo de Angelo Sanchez ${ }^{1}$, \\ Rubens Roberto Ingraci Neto ${ }^{1}$, Carlos Alberto Fortulan ${ }^{2}$, Gill Bukvic ${ }^{2}$, \\ Cesar Renato Foschini ${ }^{1}$.
}

\begin{abstract}
${ }^{1}$ Universidade Estadual Paulista, Unesp, Faculdade de Engenharia de Bauru, Dept. de Eng. Mecânica, Av. Eng. Luiz Edmundo C. Coube 14-01, CEP 17033-360, Bauru, SP, Brasil. e-mail: marcos.gon.jr@hotmail.com; sanchez@feb.unesp.br; rbnetoi@yahoo.com.br; cfoschini@gmail.com ${ }^{2}$ Universidade de São Paulo, USP, Escola de Engenharia de São Carlos, São Carlos, SP, Brasil. e-mail: cfortula@sc.usp.br; gillbukvic@yahoo.com.br
\end{abstract}

\section{RESUMO}

Os esforços de corte durante o torneamento de tarugos de alumina à verde e sua correlação com aspectos superficiais da peça foram estudados em condições experimentais. A correlação entre a força de usinagem e a taxa de remoção de material é um parâmetro importante na definição do projeto de produtos cerâmicos, já que, parâmetros inadequados produzem danos superficiais inaceitáveis na peça. O presente estudo analisou os esforços de corte obtidos durante o torneamento de peças de alumina com 99,8\% de pureza no seu estado verde e monitorou a influência da profundidade de corte nestes; utilizando-se ferramentas de corte de cermet sob condições constantes de usinagem. Os esforços de corte foram relacionados com os acabamentos superficiais, desgastes nas ferramentas e temperaturas das ferramentas durante a usinagem. Verificou-se que a profundidade de corte não afetou consideravelmente a qualidade das superfícies. Entretanto, ensaios preliminares para seleção das condições de corte, mostraram que velocidades de corte e avanços inadequados geram danos à superfície da peça. Assim, a melhor condição de corte foi a de maior profundidade de corte, 1,0 mm, uma vez que, com profundidades de corte menores aumenta-se o número de passes necessários para remoção do sobre material da peça, o que inevitavelmente leva a maior desgaste da ferramenta, maior força de usinagem e pior acabamento superficial. Destaca-se que a alumina em seu estado verde apresentou elevado efeito abrasivo sobre a ferramenta durante o torneamento. A sinterização da peça produzida na melhor condição de corte indicou que a qualidade do acabamento na superfície verde foi mantida.

Palavra-chave: cerâmica verde, usinagem, forças de corte.

\section{ABSTRACT}

In experimental conditions, cutting forces were studied during turning of green alumina billets, including their correlation with surface aspects of the workpiece. The correlation between cutting power and the removal rate are important parameters for defining the design of ceramic products, since inadequate parameters can produce excessive surface damage to the workpiece. This study examined the forces obtained during turning of alumina workpieces with $99.8 \%$ purity in their green state, by means of a three-point dynamometer, evaluating the cutting, feed and depth forces, using a cermet tool under constant machining conditions. Variables were compared with the forces, including surface finish, tool wear and temperature during machining. In the study, it was found that the depth of cut had no significant effect on the surface quality, and the cutting speed and feed influencing the finish. However, preliminary tests for selecting the cutting conditions showed that unsuitables cutting speeds and feeds generate severe damage to the workpiece surface. The best condition was $1.00 \mathrm{~mm}$ depth of cut, and the forces increasedfor with each pass performed, with the feed force the variable with greatest increases in relation to the cutting and depth forces, and wear of the cutting tool directly influenced the surface finish, generated by the highly abrasive nature of the alumina 
particles of the green compact. It is emphasized that the alumina in its green state showed high abrasive effect on the cutting tool during the turning process and the surface finishing of the green workpiece had a direct influence on the sintered workpiece.

Keywords: green ceramic, machining, cutting forces.

\section{INTRODUÇÃO}

Umas das cerâmicas mais estudadas e tradicionalmente utilizadas como cerâmica estrutural é a alumina (óxido de alumínio - $\left.\mathrm{Al}_{2} \mathrm{O}_{3}\right)$, devido a sua: elevada dureza ( 2,4 GPa - Vickers), alta resistência ao desgaste, estabilidade química, baixa densidade $\left(3,99 \mathrm{~g} / \mathrm{cm}^{3}\right)$, alta temperatura de fusão $\left(2.072{ }^{\circ} \mathrm{C}\right)$, alta resistividade elétrica e baixo custo, tendo sua matéria prima abundante [1, 2]. Apesar das cerâmicas avançadas a base de alumina apresentarem várias propriedades positivas, estes materiais também apresentam características negativas que limitam a sua aplicação, especialmente a baixa tenacidade à fratura $\left(\mathrm{K}_{\mathrm{IC}} 4 \mathrm{MPa} \cdot \mathrm{m}^{1 / 2}\right)$, responsável pela baixa resistência ao impacto e a desprezível deformação plástica [3] .

A usinagem de cerâmicas sinterizadas por retificação com rebolo de diamante é o principal processo utilizado para obtenção das tolerâncias desejadas e das qualidades superficiais, mas este processo de usinagem tem um custo elevado [4]. Para obter um acabamento de alto precisão na usinagem após a sinterização, é necessário utilizar equipamentos específicos, tornando a operação de alto custo, podendo representar até 80\% dos valores totais da produção[5].

No entanto, devido à sua alta fragilidade, os componentes invariavelmente sofrem danos, como trincas superficiais durante o processo de usinagem, resultando em perda de resistência mecânica [6, 7]. Estes danos dependem do mecanismo de remoção de material, podendo ser classificados em duas categorias: modo frágil (lascamento) e modo dúctil (deformação plástica - cisalhamento). A eficiência no processo requer uma seleção criteriosa dos parâmetros operacionais, para maximizar a taxa de remoção e controlar a integridade superficial [3]. Devido as dificuldades de usinagem de peças já sinterizadas, como alternativa pode-se utilizar dois métodos: a usinagem de cerâmica pré-sinterizada e a usinagem de cerâmica a verde.

A usinagem de cerâmica pré-sinterizada ou usinagem de cerâmica branca, é realizada após uma préqueima ( 60 - 70\% da temperatura de sinterização), usada para aumentar a resistência do material. Consequentemente, melhora-se a precisão da usinagem, principalmente em componentes cerâmicos de geometrias complexas, e também, são reduzidos os danos nas bordas. Entretanto o desgaste da ferramenta de corte é mais intenso em relação a usinagem no estado verde, o que pode elevar o custo de fabricação []].

Já a usinagem da cerâmica a verde é realizada após a etapa de compactação, sendo um processo favorável para alcançar uma forma complexa nos estágios iniciais do processamento da cerâmica, como também, reduzir as distorções geradas após a sinterização [9]. No caso de produção de lotes pequenos ou de componentes com geometrias complexas, a usinagem da cerâmica verde proporciona uma vantagem considerável em termos de qualidade, eficiência econômica e flexibilidade. Os processos convencionais de usinagem são possíveis devido à baixa resistência mecânica apresentada pelo estado verde do material, permitindo o uso de ferramentas de geometria definida e proporcionando altas taxas de remoção de material em comparação com a retificação de corpos cerâmicos sinterizados $[\underline{10}, \underline{11}]$.

No trabalho de BUCVIK et al., [12], foram torneados compactos verdes de alumina prensados de modo uniaxial, tendo-se verificado que os parâmetros de avanço, velocidade de corte e profundidade de corte, não causaram diferenças significativas na quantidade de lascamentos, e que algumas peças apresentaram lascamentos na saída da ferramenta. Observou-se também que a rugosidade dos corpos usinados acompanhou o desgaste da ferramenta de corte. No estudo de ROBERT-PERRON et al., [13], o qual realizou o torneamento de peças cerâmicas a verde, foi demonstrado que o avanço da ferramenta de corte era o parâmetro mais influente sobre os lascamentos nas bordas das peças, sendo sugerido o emprego de avanços de 0,0635 à 0,1016 $\mathrm{mm} / \mathrm{rev}$ a fim de evitar estes danos.

Na pesquisa conduzida por MAIER e MICHAELI [10], foram torneados compactos de alumina com 99,7\% de pureza. Os autores observaram que o aumento da velocidade de corte reduziu levemente a rugosidade superficial das peças, permanecendo a Fc praticamente constante; o aumento do avanço, por sua vez, resultou no aumento de ambos; enquanto incrementos na profundidade de corte levaram a discreta melhora da rugosidade, mas ao aumento expressivo da Fc.

Uma vez que o desgaste da aresta principal de corte progride, a área de contato da peça com a superfície principal de folga aumenta, consequentemente, a força de usinagem também é elevada. A variação dos esforços de corte pode ser usada para monitorar o desgaste da ferramenta, garantindo, de forma indireta, o acabamento da peça usinada, bem como suas tolerâncias. [14]. 
O objetivo deste trabalho foi verificar a influência das forças de corte e dos parâmetros de usinagem na superfície do corpo de alumina a verde, analisando o acabamento superficial e a rugosidade. O desgaste da ferramenta também foi medido, visando relacionar sua influência nos esforços e no acabamento superficial. As amostras foram submetidas à operação de torneamento com três profundidades de corte distintas. As forças de usinagem e as temperaturas alcançadas pelas pontas das ferramentas de corte foram monitoradas durante os ensaios.

\section{MATERIAIS E MÉTODOS}

Para produzir os compactos verdes, utilizou-se uma mistura de pós de Alumina Calcinada A1000-SG (Almatis, Inc., 99,8\% de pureza, com área superficial de $7,7 \mathrm{~mm}^{2} / \mathrm{g}$ e $\rho_{\text {real }}=3,99 \mathrm{~g} / \mathrm{cm}^{3}$ ) com auxiliadores de processo, a mistura foi realizada em moinho de bolas com elementos cilíndricos de zircônia (Ø 12,0 mm x 12,0 mm). Uma suspensão com 30 \% em volume de alumina em pó foi dispersa num volume de 68 \% de água destilada e deionizada e foram acrescentados 1 \% em volume de PVAl (álcool polivinílico - Vetec Química Fina Ltda - MW 22,000) como ligante e 1 \% em volume de poliacrilato de amônia (Dispersal 130 da Lubrizol) como lubrificante. Usou-se defloculante associado à mistura mecânica, a fim de garantir uma dispersão mais homogênea da mistura. A mistura foi seca pela técnica de secagem de “Spray-Dryer”, resultando em aglomerados esféricos de partículas de alumina, tendo a fluidez necessária para o preenchimento eficiente dos moldes. A figura 1, obtida por meio de Microscopia Eletrônica de Varredura (MEV), ilustra o pó utilizado no trabalho, na qual se observa o aglomerado de partículas de formato circular.
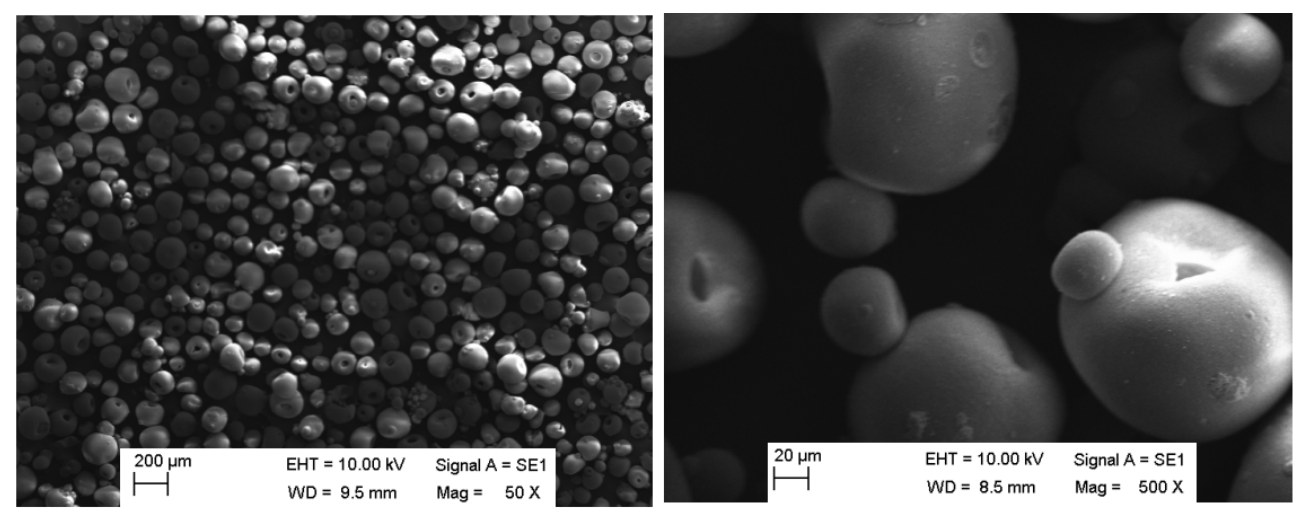

Figura 1: MEV da alumina produzida pelo método de "spray dryer”.

Depois de produzido o pó, os corpos-de-prova foram conformados em formato cilíndrico com dimensões de $\varnothing$ 15,0 mm x 24,0 mm. Para a compactação de cada peça foi utilizada 9,8 gramas de alumina. Os corpos foram prensados em processo uniaxial de simples ação com 120 MPa e, posteriormente, por prensagem isostática, por meio da técnica Wet Bag, com 200 MPa. A figura 2, obtida em microscópio Confocal, ilustra o aspecto visual do compacto após a etapa de prensagem.

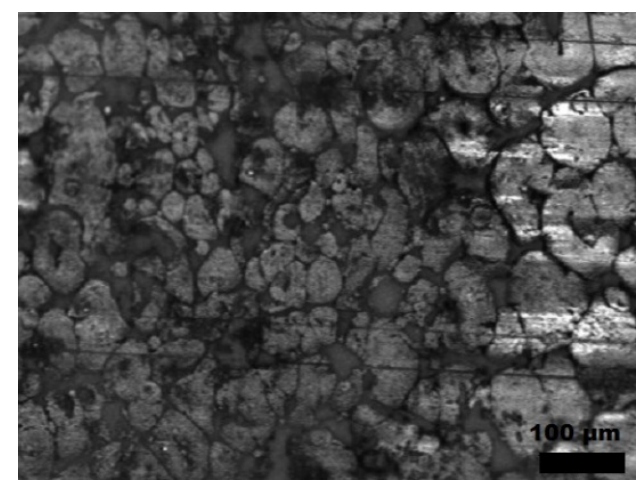

Figura 2: Imagem de microscopia confocal do compacto após a etapa de prensagem.

A operação de usinagem foi realizada em uma fresadora universal modelo ZOCCA U-30, adaptada para o torneamento. A escolha da fresadora para os ensaios de usinagem deve-se a sua alta rigidez e facilida- 
de de configurá-la de maneira adequada ao processo, além de facilitar o monitoramento com o dinamômetro e demais instrumentos. O compacto foi fixado no cabeçote vertical da máquina, proporcionando o movimento de rotação da peça. A ferramenta de corte foi fixada no suporte do dinamômetro, sendo o dinamômetro preso sobre a mesa da máquina a qual gerou o avanço quando deslocada verticalmente e a profundidade de corte quando movimentada na horizontal.

Os compactos foram fixados em um suporte metálico por adesão com cera térmica, o que garantiu uma rígida fixação e propiciou uma fácil remoção da peça pelo aquecimento a $100^{\circ} \mathrm{C}$. A fixação na pinça da máquina de usinagem ocorreu através do suporte.

Os esforços de corte foram captados por um dinamômetro de três coordenadas da Kistler - 9257BA conectado a unidade de controle 5233A1 que possui um filtro passa-baixo de $200 \mathrm{~Hz}$ e permite a seleção do range apropriado para os esforços em cada direção ( $5 \mathrm{kN}$ no sentido do eixo $\mathrm{Z}$ e $2 \mathrm{kN}$ para os eixos $\mathrm{X}$ e Y). As saídas coaxiais da unidade de controle do dinamômetro estão conectadas a um módulo de aquisição de dados analógicos da National Instrument, modelo NI-9207, que se comunica a um computador por meio do chassi ethernet cDaq-9188. Através do dinamômetro, foi possível mensurar os esforços de usinagem. Um programa foi desenvolvido em ambiente LabView ${ }^{\circledR}$, para atuar como interface da conexão e gravação dos dados captados pelo chassi à um computador.

$\mathrm{O}$ avanço e a velocidade de corte foram selecionados por meio de ensaios preliminares nos quais diversas condições foram testadas. $\mathrm{O}$ aspecto visual das superfícies produzidas, ou seja, a não ocorrência de lascamentos e outros danos, foi o critério para seleção dos parâmetros de corte adequados ao estudo. As imagens das peças foram obtidas por meio de um estéreo microscópio ótico da Nikon, modelo SMZ800, acoplado a uma câmara digital de alta resolução. A rugosidade superficial dos corpos de prova durante os ensaios finais foi mensurada em um microscópio Confococal LEICA DCM3D. A microscopia Confocal permitiu a obtenção da rugosidade das amostras sem o contato físico; em um perfilômetro convencional poder-se-ia obter leituras imprecisas com a remoção de aglomerados durante o deslocamento do sensor. Quatro medidas de Ra (Rugosidade Média Aritmética) e Rq (Rugosidade Média Quadrática) foram executadas a cada amostra, com cutoff de $0,8 \mathrm{~mm}$.

O processo de sinterização dos compactos foi realizado em um forno elétrico do tipo câmara, da marca Lindberg Blue ${ }^{\circledR}$, com uma rampa de aquecimento $\left(4,44^{\circ} \mathrm{C} / \mathrm{min}\right)$, e rampa de resfriamento similar, com patamar de 2 horas à $1600^{\circ} \mathrm{C}$, tendo duração total do processo em torno de 14 horas.

A ferramenta de corte usada para o torneamento é de cermet sem revestimento e sem quebra-cavacos com raio de ponta de 0,05 mm (TPGB 1103005 TN60), acoplada a um porta-ferramentas modelo STGPL 1212-H-11, ambos comercializadas pela Kyocera. A escolha por um inserto sem quebra-cavacos visa facilitar a análise de seu desgaste, já que o material cerâmico em seu estado verde é abrasivo. A norma ISO 3685 define o desgaste de flanco máximo $\left(\mathrm{VB}_{\mathrm{Bmax}}\right)$ mensurado em cada ensaio. Para cada condição de corte testada utilizou-se uma nova aresta da ferramenta de corte. Os desgastes das ferramentas de corte foram mensurados por meio de análise microscópica.

Depois de fixados velocidade de corte $(V c)$ e avanço $(f)$, os ensaios definitivos foram realizados com profundidades de corte ( $a p$ ) de 0,25 mm, 0,5 mm e 1,0 mm. Para cada configuração de corte vários passes de corte ocorreram até que um sobrematerial de $4 \mathrm{~mm}$ no diâmetro do compacto verde fosse removido. Assim, para a primeira condição de ensaio foram necessários oito passes, quatro passes para a segunda e dois passes na terceira. A profundidade de corte foi estabelecida como variável, pois dependendo do volume de material removido, pode-se causar danos e lascamentos nas bordas dos compactos a verde, mesmo em situações com boa rugosidade superficial. Os valores selecionados para velocidade de corte e avanço foram $33,4 \mathrm{~m} / \mathrm{min}$ e $0,03 \mathrm{~mm} / \mathrm{rev}$ respectivamente, após uma avaliação dos acabamentos superficiais utilizando diversos parâmetros de corte.

Dois termopares foram empregados durante a usinagem, um microtermopar tipo K, para monitoramento da temperatura da ferramenta, e um termopar tipo J, para registrar a temperatura do ambiente. O microtermopar foi posicionado em contato com a superfície de saída da ferramenta de corte a 1,2 $\mathrm{mm}$ da extremidade da aresta de corte. Para sua fixação foi fabricado um suporte em resina epóxi conforme as dimensões da ferramenta para um encaixe adequado, com um canal interno revestido de silicone para inserir e fixar permanentemente o microtermopar no molde, facilitando a remoção do mesmo da ferramenta e evitando erros de posicionamento a cada novo ensaio.

A Figura 3 ilustra o fluxograma do processo, e a Figura 4 demonstra a montagem esquemática do banco de ensaios. Os esforços de corte em cada direção estão representados por: Fx - força de corte (Fc); Fz força de avanço (Ff); e Fy - força de penetração (Fp). 


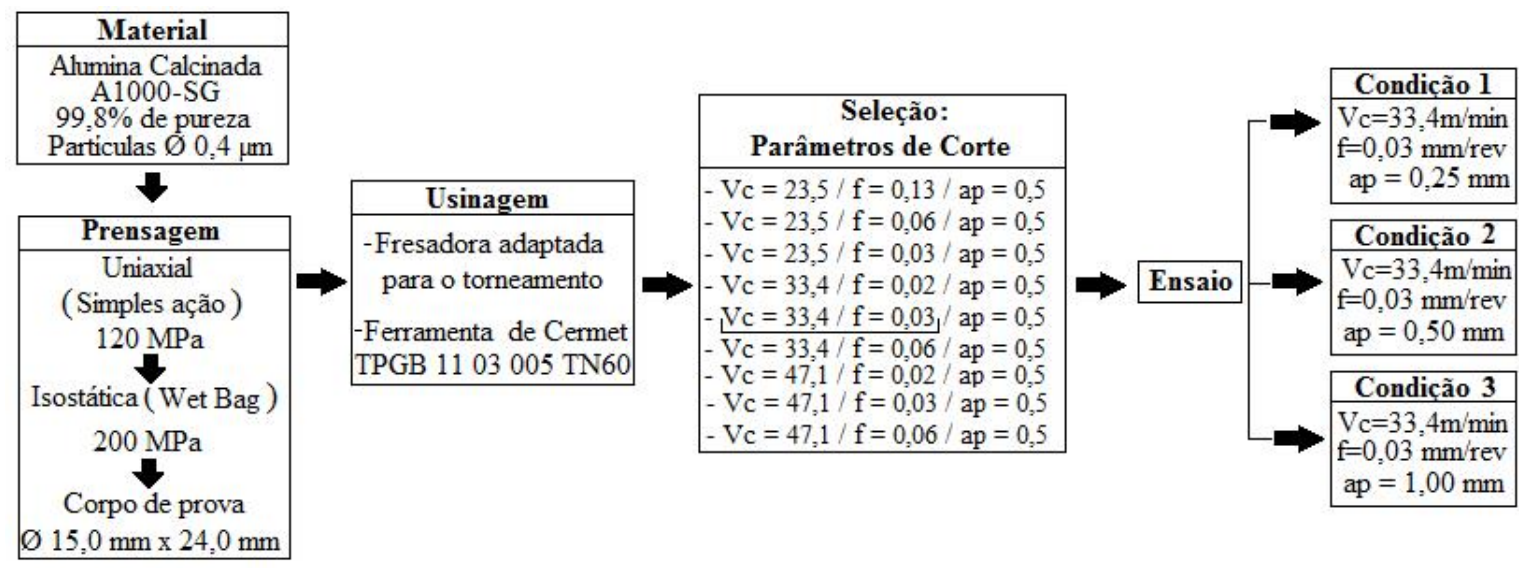

Figura 3: Fluxograma de procedimentos.

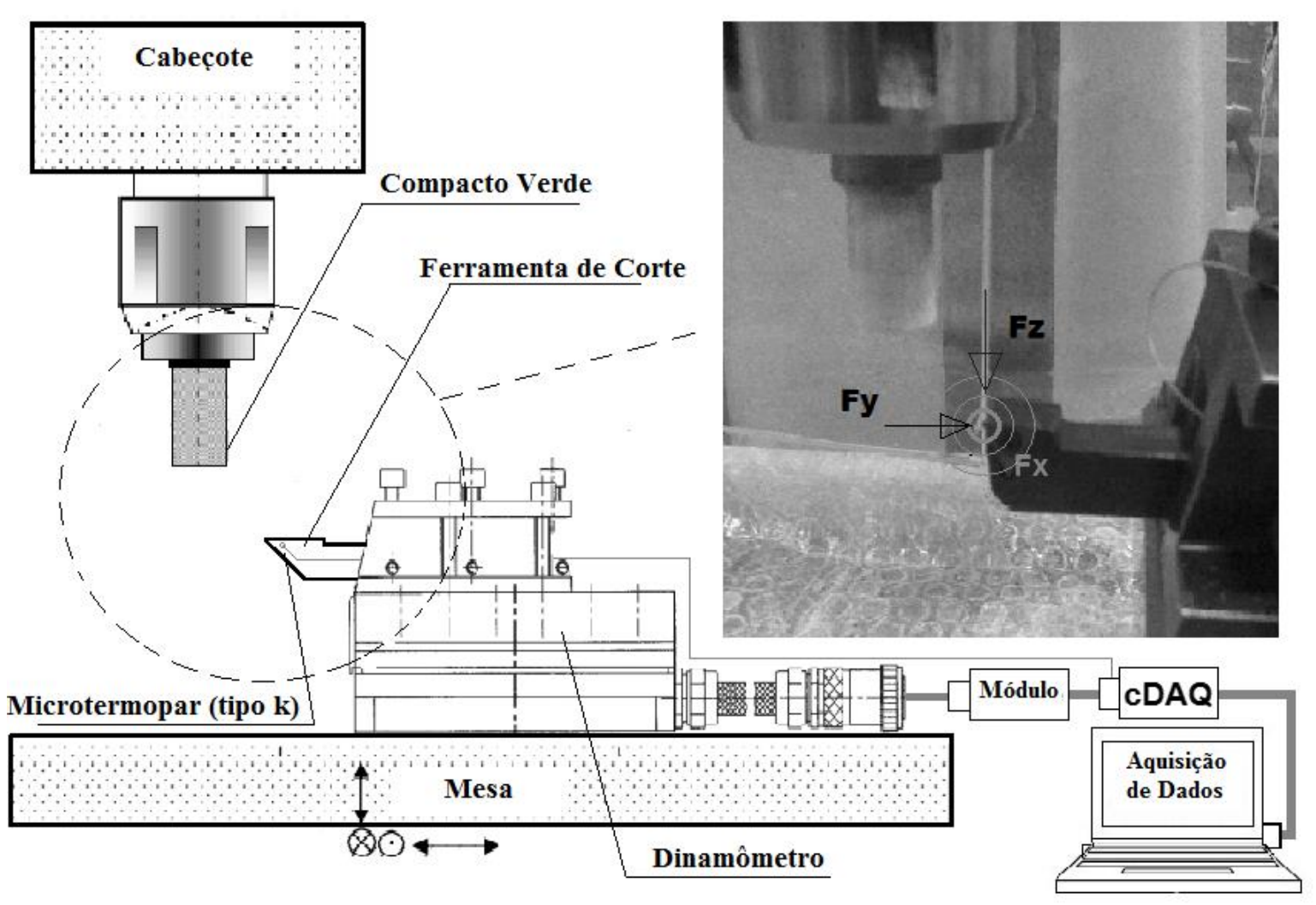

Figura 4: Montagem esquemática do banco de ensaios de usinagem.

\section{RESULTADOS E DISCUSSÃO}

Os acabamentos superficiais dos corpos cerâmicos dos ensaios preliminares são apresentados na Figura 5. Estes corpos de prova foram usinados mantendo-se constante o ap e variando-se a $V c$ e o $f$. A melhor condição de corte encontrada nesta etapa foi $V_{c}=33,4 \mathrm{~m} / \mathrm{min}$ e $f=0,03 \mathrm{~mm} / \mathrm{rev}$; as demais configurações de corte apresentaram problemas como o aspecto visual ruim e não uniformidade da superfície. 


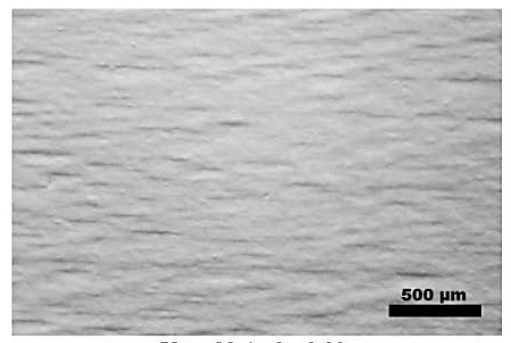

$\mathrm{Vc}=33,4-\mathrm{f}=0,02$

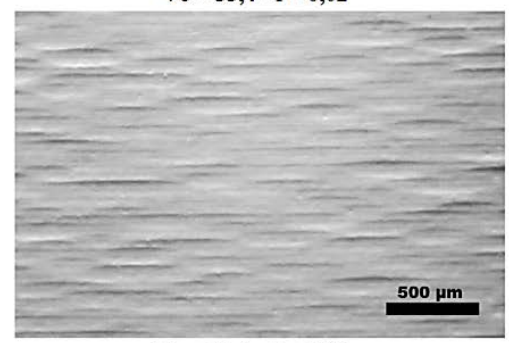

$\mathrm{Vc}=33,4-\mathbf{f}=0,06$

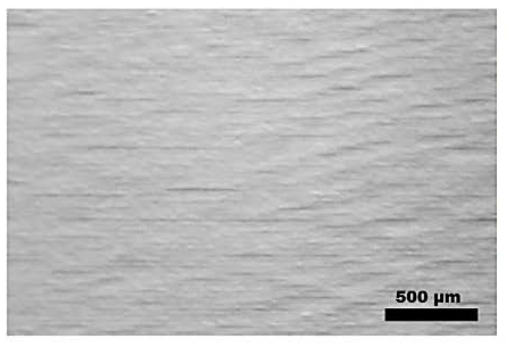

$\mathrm{Vc}=33,4-\mathrm{f}=0,03$

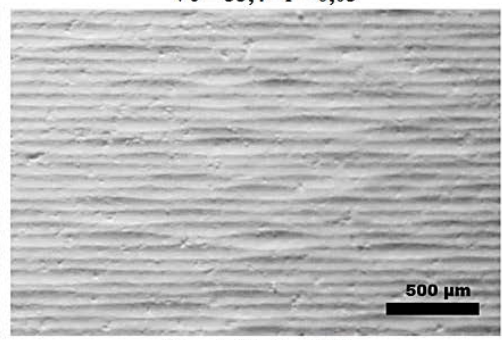

$\mathrm{Vc}=47,1-\mathrm{f}=0,06$

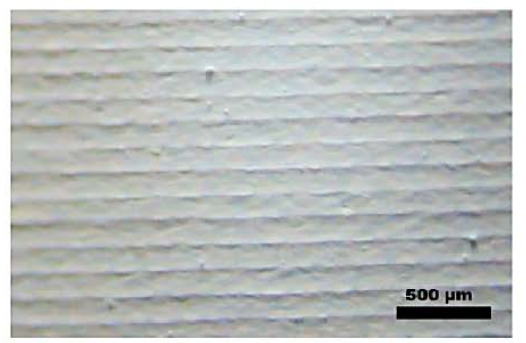

$\mathrm{Vc}=23,5-\mathrm{f}=0,13$

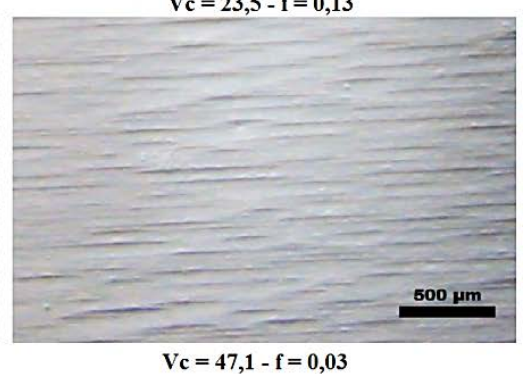

Figura 5: Aspecto visual dos ensaios preliminares após a usinagem mantendo-se constante a profundidade de corte de $0,50 \mathrm{~mm}$ e variando-se $V c(\mathrm{~m} / \mathrm{min})$ e $f(\mathrm{~mm} / \mathrm{rev})$.

Uma possível explicação para o valor de avanço inferior a $0,03 \mathrm{~mm} / \mathrm{rev}$ não propiciar o melhor acabamento, como ocorre no corte de metais, é o fato do corte a $0,03 \mathrm{~mm} / \mathrm{rev}$ propiciar a remoção intragranular dos aglomerados e ter menor probabilidade do pó removido permanecer entre a peça e aresta de corte, como uma aresta postiça.

A Figura 6 traz alguns danos severos gerados após a usinagem com parâmetros inadequados, sendo ap de $0,50 \mathrm{~mm}, V c$ de $65,9 \mathrm{~m} / \mathrm{min}$ e $f$ de $0,03 \mathrm{~mm} / \mathrm{rev}$. A ocorrência de danos pode ser provocada pela força de corte empregada na usinagem, como também, as altas tensões desenvolvidas que causam desprendimento das partículas compactadas, uma vez que a peça verde compactada apresenta baixa resistência mecânica.

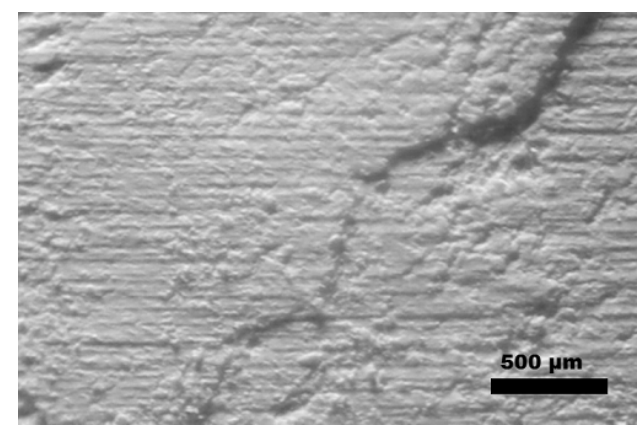

Figura 6: Danos visuais após a usinagem utilizando: ap de $0,50 \mathrm{~mm}, V c$ de $65,9 \mathrm{~m} / \mathrm{min}$ e $f$ de $0,03 \mathrm{~mm} / \mathrm{rev}$.

Verificou-se que a velocidade de corte e o avanço tiveram forte influência no acabamento, parâmetros inadequados produziram danos superficiais excessivos na peça, especialmente o aparecimento de pequenos vazios caracterizados como destacamentos de aglomerados do material. Na Figura 7, são expostos os compactos após a usinagem com as três condições estabelecidas para os ensaios definitivos. 


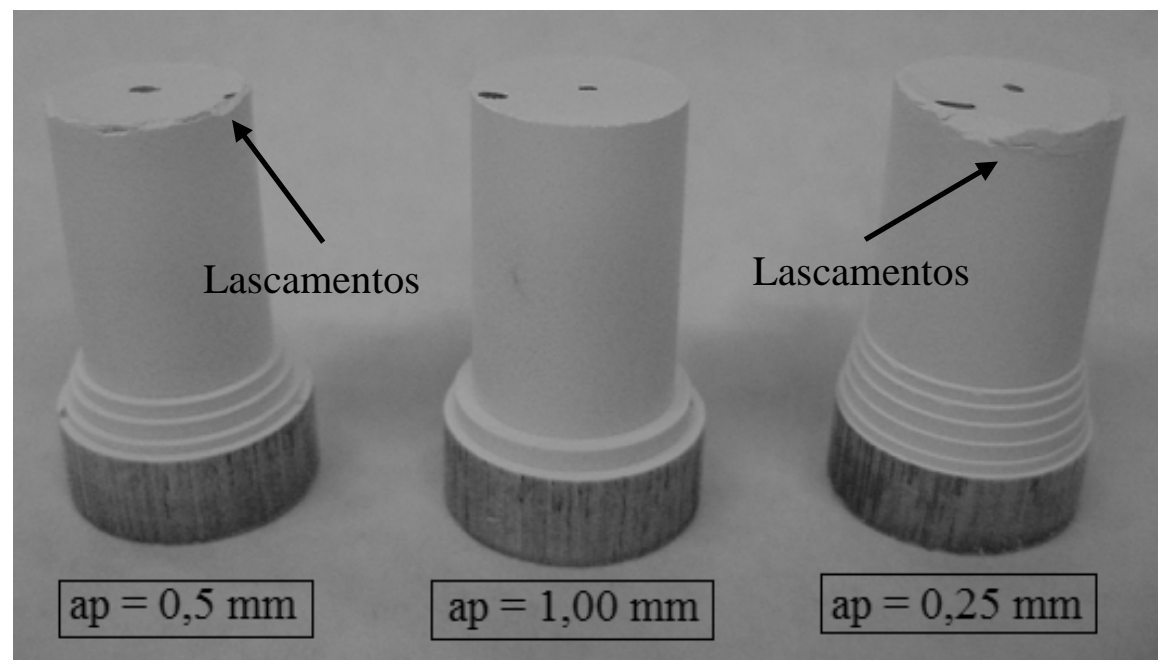

Figura 7: Compactos após a usinagem.

Durante os ensaios na primeira condição não foram realizados os oitos passes estabelecidos, somente seis passes. Pois, notou-se que o compacto verde apresentou lascamento ao redor de toda a borda superior, sendo inviável continuar o processo. Na segunda condição verificou-se que o compacto apresentou lascamento na borda ao final dos quatros passes. Desta forma, a remoção de material com profundidades de corte de 0,25 e $0,50 \mathrm{~mm}$ foram consideradas inadequadas neste estudo.

Por outro lado, na terceira condição testada com ap de $1,00 \mathrm{~mm}$, o compacto não apresentou danos na borda ao final dos passes realizados, obtendo-se a remoção de todo o sobrematerial, 4 mm do diâmetro. Dois dos maiores desafios na usinagem verde são evitar lascamentos nas bordas e prevenir o desenvolvimento de danos internos causados por tensões de compressão [15]. O aspecto visual da borda superior e da superfície do compacto verde em cada condição após a usinagem é identificado na Figura 8.

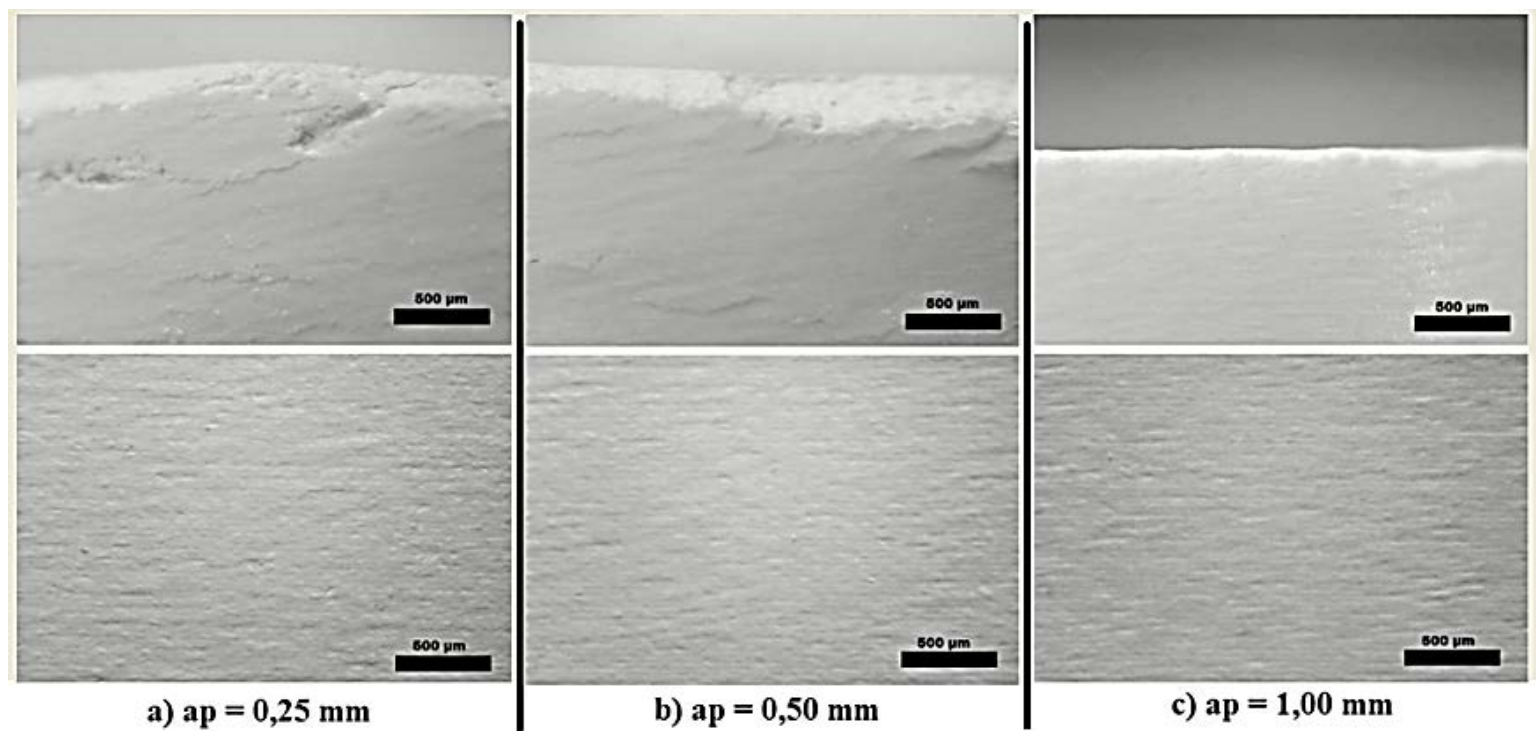

Figura 8: Aspecto visual da borda dos compactos e das superfícies em cada condição de corte.

Observou-se que os acabamentos superficiais das três condições de corte foram satisfatórios, apresentando boa qualidade superficial, mesmo com danos severos nas bordas dos compactos. Assim, a profundidade de corte não teve efeito considerável sobre a rugosidade da superfície usinada. Os ensaios demonstraram que a superfície final deve ser alcançada com a menor quantidade de passes possíveis, pois diminui o desgaste da ferramenta e consequentemente reduz os esforços com manutenção da qualidade da superfície [16].

A Figura 9, demonstra os esforços em cada condição estabelecida, onde: Fz é a força de avanço (Ff), Fx é a força de corte (Fc) e Fy é a força de pentração (Fp). A Figura 10 traz os desgastes de flanco das fer- 
ramentas de corte utilizadas em cada condição. Nota-se um aumento progressivo de desgaste a cada passe.

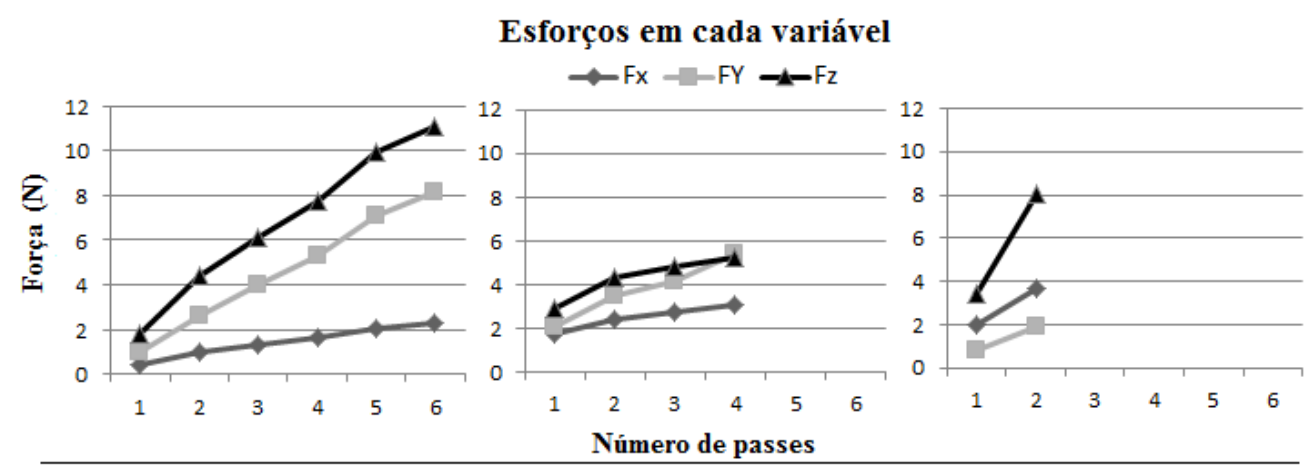

a) ap $=0,25 \mathrm{~mm}$

b) ap $=0,50 \mathrm{~mm}$

c) ap $=1,00 \mathrm{~mm}$

Figura 9: Esforços de corte por passe em cada condição.

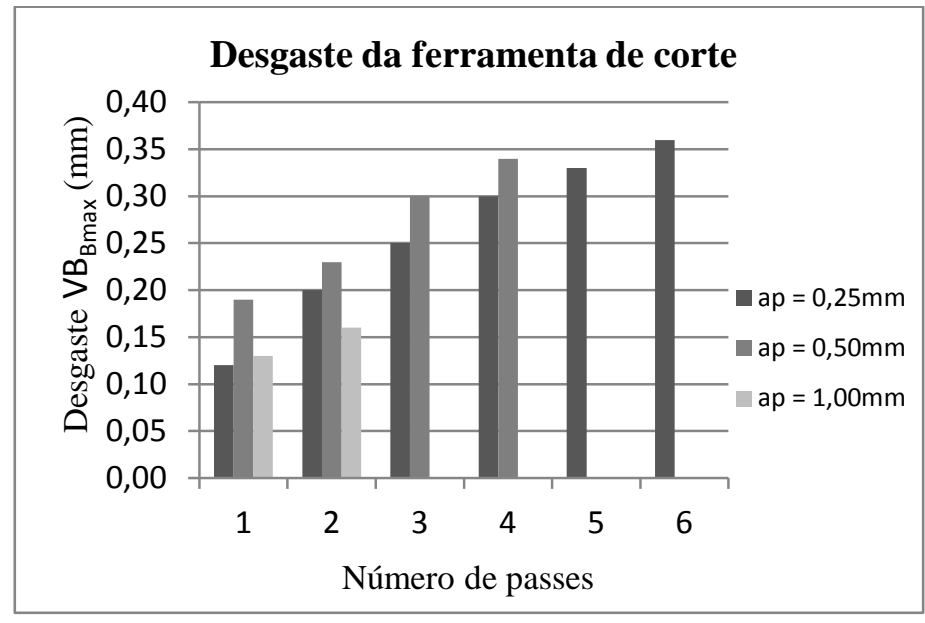

Figura 10: Desgaste de flanco máximo $\left(\mathrm{VB}_{\mathrm{Bmax}}\right)$ da ferramenta de corte em cada condição.

Verificou-se que os esforços de corte aumentaram em cada passe. $\mathrm{O}$ aumento do desgaste da aresta de corte resultou em um aumento da área de contato entre a ferramenta e a peça, o que ocasionou aumento das forças de corte e piora da qualidade superficial. Pode ser visto que, na primeira condição, a força de avanço alcançou $11 \mathrm{~N}$ e a força de penetração $8 \mathrm{~N}$, valores altos se forem comparados com as outras condições. Já a força de corte, para todas as condições de corte, teve um aumento gradual conforme os passes foram executados, e também com o aumento da profundidade de corte, mas com amplitude menor do que as demais.

Uma provável causa das maiores forças de avanço (Fz) em todas as condições é a ampliação da área de contato entre ferramenta e peça com o aumento do desgaste de flanco, o que leva ao incremento dos esforços de corte na direção axial.

Observou-se que quanto maior a profundidade de corte mais elevados foram os esforços de corte, devido ao atrito mais intenso da ferramenta de corte com a peça. A maior profundidade de corte levou ao menor desgaste de flanco para a remoção de todo o sobrematerial. A primeira condição teve desgaste inicial menor, mas no decorrer da usinagem esta taxa se elevou, assim como na condição com ap de 0,5 mm.

A Figura 11 expõe as rugosidades superficiais, Ra $(\mu \mathrm{m})$ e $\mathrm{Rq}(\mu \mathrm{m})$, dos três compactos usinados; permitindo uma análise da influência do desgaste da ferramenta na qualidade da superfície. 


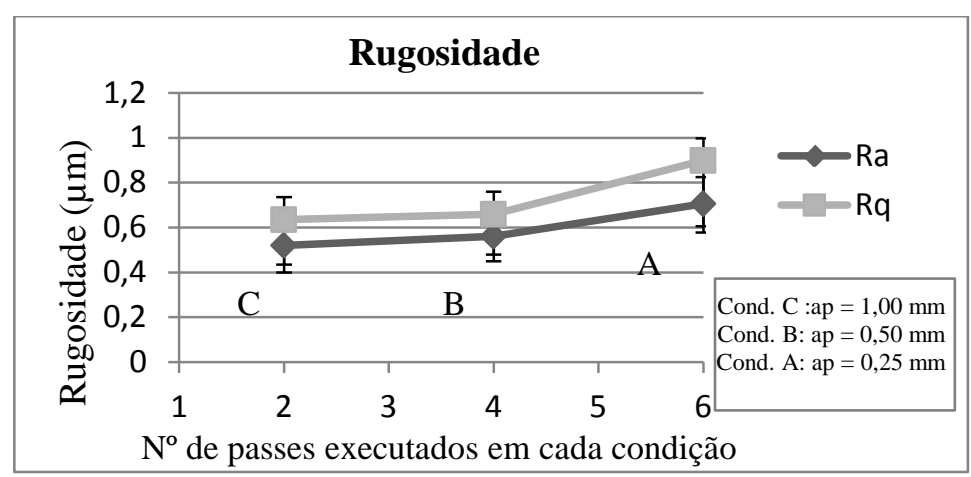

Figura 11: Rugosidade superficial dos compactos a verde em cada condição.

A Figura 11 evidencia o aumento da rugosidade com a execução de mais passes para remoção do sobrematerial, ou seja, há piora no acabamento da peça com o avanço do desgaste da ferramenta de corte. A menor rugosidade foi obtida utilizando profundidade de corte de $1,0 \mathrm{~mm}$, que é a situação de menor número de passes, logo é situação indicada como a mais adequada. Portanto, o aumento do ap não levou ao incremento considerável da taxa de desgaste da ferramenta, logo, com menos passes sendo executados o desgaste provocado na ferramenta será menor e o acabamento superficial melhor.

A Figura 12 mostra as ferramentas de corte ao final dos ensaios, verificando-se maior desgaste de flanco na condição de menor ap.

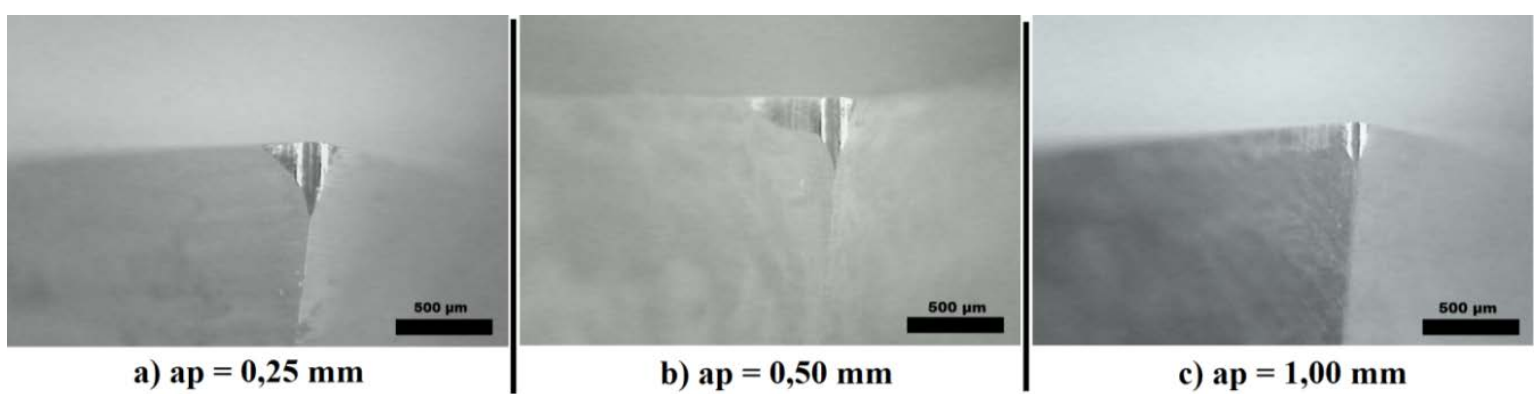

Figura 12: Desgaste gerado nas ferramentas ao final dos ensaios.

Ainda que a ferramenta de corte de cermet apresente $1800 \mathrm{HV}$ à temperatura ambiente, a usinagem de alumina a verde causou um intenso desgaste por abrasão. O compactado verde possui baixa resistência mecânica que durante a usinagem levou a remoção de pequenos aglomerados e pó, sem adesão com a ferramenta de corte; entretanto, a dureza da cerâmica torna-a abrasiva.

A Figura 13 demonstra a variação das temperaturas médias, máximas e mínimas registradas durante os ensaios nas diferentes condições utilizadas. 


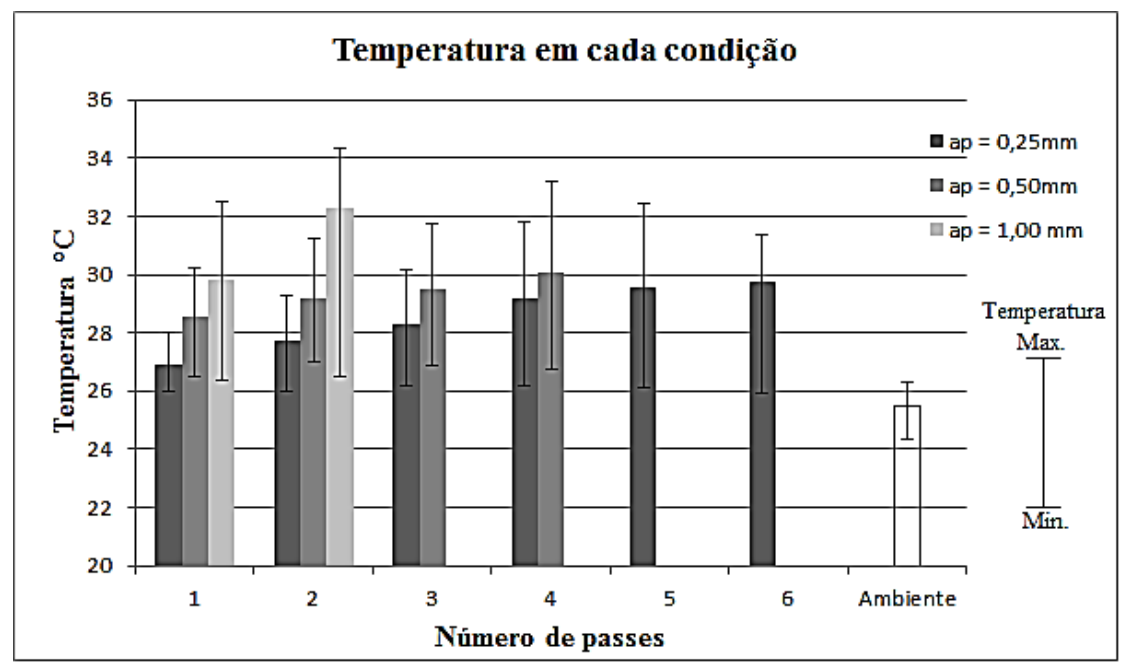

Figura 13: Temperaturas registradas em cada condição.

A Figura 13 aponta que a máxima temperatura atingida pelo termopar foi de $34,5^{\circ} \mathrm{C}$, não sendo, pois, significante para alteração das propriedades mecânicas da ferramenta. Portanto, a temperatura não teve influência no processo de usinagem, independentemente dos parâmetros utilizados.

Depois dos ensaios a integridade superficial dos compactos foi verificada; a melhor condição observada foi com a profundidade de corte de 1,00 mm. Em seguida o corpo de prova desta condição foi sinterizado (c), para uma análise do acabamento superficial. Para comparação da qualidade da superfície foram sinterizados também um compacto sem usinar (a), e um usinado com condição inadequada (b), estes são representados nas imagens de MEV da Figura 14.
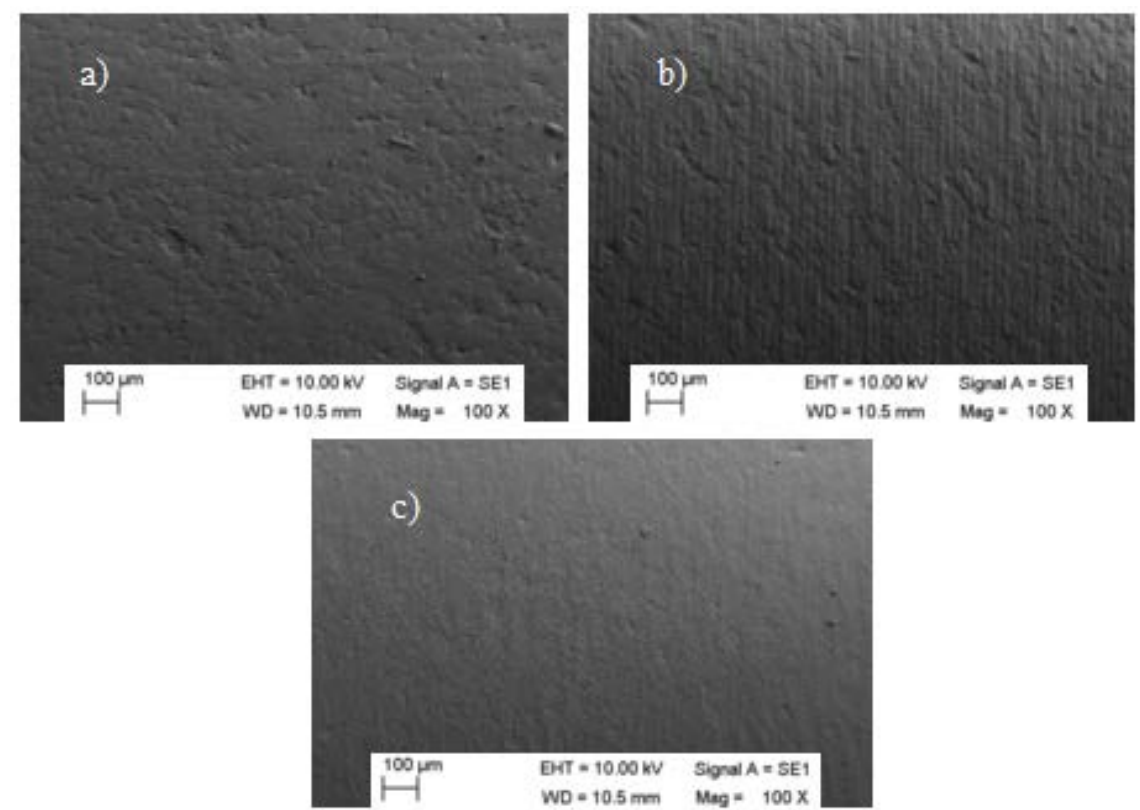

Figura 14: Acabamentos superficiais obtidos após a sinterização: (a) sem usinar, (b) usinado com condição inadequada e (c) condição adequada.

Observa-se na Figura 14 o bom acabamento superficial após a sinterização na condição adequada (c), assim como obtido no estado verde; já o acabamento foi inadequado na condição (b). O acabamento superficial da peça a verde teve influência direta na peça sinterizada, sendo a usinagem da cerâmica no estado verde benéfica para melhoria do acabamento após a sinterização.

\section{CONCLUSÕES}


No presente trabalho verificou-se o aumento da força de usinagem com o incremento da profundidade de corte. No entanto, a profundidade de corte não interfere na qualidade superficial tanto quanto influenciam a velocidade de corte e o avanço. Durante o torneamento os maiores esforços foram registrados na direção de avanço (Fz), sendo que o desgaste das ferramentas e os parâmetros de corte mais severos levaram a elevação destes. Obteve-se a melhor qualidade de peça na condição com profundidade de corte de 1,00 mm, em que não houve danos na borda.

O desgaste da ferramenta de corte teve influência direta na rugosidade das peças usinadas em verde devido a degradação constante da ferramenta de corte, sendo a abrasão o mecanismo de desgaste predominante. $\mathrm{O}$ aumento da temperatura da ferramenta durante o corte não teve influência no processo de usinagem.

Conclui-se que o acabamento superficial da peça a verde teve influência direta no acabamento da peça sinterizada, sendo benéfica a usinagem da cerâmica no estado verde para melhoria do acabamento superficial da peça após a sinterização.

\section{BIBLIOGRAFIA}

[1] WEFERS, K., MISRA, C. Oxides and hydroxides of aluminum. Alcoa Laboratories: Alcoa Technical. Paper n'. 19, 1987.

[2] KUMAR, A. S., DURAI, A. R., SORNAKUMAR, T. "Development of alumina-ceria ceramic composite cutting tool”, International Journal of Refractory Metals e Hard Materials, v. 22, pp. 17-20, 2004.

[3] ARGAWAL, A., RAO, P. V. "Experimental investigation of surface/subsurface damage formation and material removal mechanisms in SiC grinding”, International Journal of Machine Tools \& Manufacture, v. 48, pp. 698-710, 2008.

[4] BESSHI, T., SATO, T., TSUTUI, I. “Machining of alumina green bodies and their dewaxing”, Journal of Materials Processing Technology, v. 95, pp. 133-138, 1999.

[5] DESFONTAINES, M., JORAND, Y., GONON, M., et al., Characterisation of the green machinability of AlN powder compacts, Journal of the Europem Ceramic Society, v. 25, pp. 781-791, 2005.

[6] AYDIN, A., BRISCOE, B. J., SANLITURKB, K. Y. "Dimensional variation of diepressed ceramic green compacts: comparison of a finite element modelling with experimente”, Journal of the European Ceramic Sociery, v. 17, pp. 1201-1212, 1997.

[7] STRAKNA, T. J., JAHANMIR, S., ALLOR, R. L., et al. "Influence of grinding direction on fracture strength of silicon nitride”, Journal of Engineering Materials and Technology, v. 118, pp. 335-342, 1996.

[8] LI, J. J., WU, T., YU, Z. Y. M., et al., “Micro machining of pre-sintered ceramic green body”, Journal of Materials Processing Technology, v. 212 ,pp. 571 - 579, 2012.

[9] WESTERHEIDE, R., DRÜSEDAU, K. A., HOLLSTEIN, T., et al., "Advances in characterisation of machined green compacts”, Journal of the Europem Ceramic Society, v. 17, pp. 467-472, 1996.

[10] MAIER, H. R., MICHAELI, N. “Green machining of alumina”, Key Eng. Mater, v.132-136, pp.436-439, 1997.

[11] JANSSEN, R., SCHEPPOKAT,S., CLAUSSEN, N. “Tailor-made ceramic-based componentes Advantages by reactive processing and advance shaping techniques”, Journal of the European Ceramic Society, v. 28, pp. 1369-1379, 2008.

[12] BUKVIC, G., SANCHEZ, L. E. A., FORTULAN, C.A. "Green machining oriented to diminish density gradient for minimization of distortion in advanced ceramics”, Machining Science and Technology, v. 16, pp. 228-246, 2012.

[13] ROBERT-PERRON, E., BLAIS, C., PELLETIER, S. "Machinability of green powder metallurgy components: part I. characterization of the Influence of tool wear", The Minerals, Metals \& Materials Society and ASM International, 2007.

[14] MATA, F., GAITONDE, V. N., KARNIK, S. R., et al., "Influence of cutting conditions on machinability aspects PEEK, PEEK CF 30 and PEEK GF 30 composites using PCD tools”, Journal of Materials Processing Technology, v. 209, pp. 1980-1987, 2009.

[15] HERLINGER, J., SCHOETTMER, G., ZIMMER, J. “Optimizing Green Machining”, Ceramic Industry, v. 156, ed. 2, pp. 22-25, 2006.

[16] SHEPPARD, L. M. “Green machining - tools and considerations for machining unfired ceramic”, Ceramic Industry, p. 65-76, 1999. 